contained in the blood. It is no surprise to me to learn that morphine causes albuminuria-on the contrary, it is just what I should expect; - but 1 am quite unable to agree with the suggestion of Dr. Huchard that the albuminuria is due to the diminution of arterial tension; for, in the first place, as you remark, this cannot apply to granularkidney, in which the tension is very high, and I would add (as the late Dr. Mahomed pointed out) may be so before there is any albuminuria; and, secondly, the low tension of the mor phine habit is by no means continuous, but alternates between doses with extreme high tension (a fact previously pointed out by others), and it is to this ligh tension that I should attribute the albuminuria; for in another paper read at the meeting at Leeds, I attenpted to show that high tension may be the actual cause of albuminuria. There are several other facts which might, I think, be adduced against Dr. Huchard's suggestion that the albuminuria is due to the low tension, or that low tension per se will cause passive congestion of organs, but to go into these at sufficient length would lead me beyond the limits of a letter. While, therefore, I look upon the facts mentioned as of extreme interest and as tending to confirm in some important respects the results of my researches, I believe that it may be possible to give a better explanation of the causation of albuminuria by morphine than that suggested by Dr. Huchard.

I am, Sirs, yours truly,

Welbeck-street, W., May 26th, 1890.

A. HAIG.

\section{A POINT IN CONNEXION WITH GUNSHOT WOUNDS OF THE HEAD.}

To the Editors of $\mathrm{TH} \mathrm{E} \mathrm{LANCET}$.

SIRS,-The other day when reading through the operations of surgery written by Mr. W. H. A. Jacobson in the article on "Operative Interference in the Case of Foreign Bodies in the Brain," the following footnote on p. 206 attracted my attention:-“"Mr. Barwell (Clin. Soc. Trans., vol. xviii., p. 232) makes the following observation, which is of importance if it is found to be constant-viz, that, though the weapon may be held very close, there will be neither scorching nor powder-tattooing, if the bullet be driven by one of the modern fulminates contained in the same cap with the projectile." The following case of suicide which occurred during Sir Robert Sandeman's expedition through the Gomal Pass in January last may prove of interest to your readers, as it illustrates the correctness of Mr. Barwell's remark. $\mathrm{M}-$-, a Hindu, wandered away from our camp on the morning of Jan. 25th at Kajuri Kuch, and committed suicide by shooting himself with his revolver in the head. The man's body was found about 9 A.M. the same day by some of the Baluch Levy sowars who were with the expedition. On my arrival I found the suicide lying on his back quite dead, with a Webley's revolver (1890 pattern) in his right hand. There was a large wound of entry in the right temple, half an inch above and one inch and threequarters behind the right external angular process, and a larger wound of exit two inches above and one inch behind the left mastoid process, but there was not the slightest scorching or blackening of the edges of the wound of entry from the effects of the powder, and I made a note of this at the time. The chambers of the revolver were all loaded except one, and that had recently been discharged. The man's body lay on the sandy bed of the Zhob river close to the bank, and tracking his footprints showed he had walked right up to the bank, had then turned and faced the sun, and, having placed the muzzle of his revolver against his right temple, had pulled the trigger. The footprints further showed he had, after discharging his revolver, managed to stagger seven steps away from the bank before falling to the ground. In the dead man's waistcoat pocket a slip of paper was found, on which was written a statement in his own handwriting saying he intended to commit suicide. I may mention the Webley's revolver referred to carries a -450 cylindro-conoidal bullet and a heavy charge of powder. and that the man, hailing from the north of India, possessed a skin with but little pigment in it.

I am, Sirs, yours truly,

A. W. D. LEAHY, F.R.C.S.,

Officiating Residency Surgeon, Hyderabad,

\section{BOQUS DIPLOMA MANUFACTORIES OF THE UNITJD STATES."}

To the Editors of THE LANCET.

Sins,-That the large number of American students always to be found in England and on the Continent may be put in a proper light, and not be made to suffer additional indignities by the action of the University of Berlin, I beg space to reply to your article of the 19th ult., entitled "Bogus Diploma Manufactories of the U.S."

In 1889, forty-eight of our colleges required three or more courses of lectures, ${ }^{1}$ and 114 required an entrance examination ; of these, at least twelve require an entrance examination equal to the preliminary examinations of the Examining Boards of ( Treat Britain, and none of these twelve have less than a three-years' graded course of study. They are Har vard, Yale, the University of Pennsylvania, University of Minnesota, University of California, College of Physicians and Surgeons in the City of New York (Medical Departmen of Columbia College), Albany Medical College (Medical Department of Union University), Niagara University, Chicago Medical College, Cooper Medical College, Sain Louis Medical College, and the Minneapolis College of Physicians and Surgeons. While some of these are comparatively young Colleges, others are old and well known, and all have faculties that have the entire confidence of the profession. We think it as unjust for men holding such diplomas to be denied recognition in Berlin of their time of study because a great many Germans obtained bogus American diplomas, as you think it unjust of France to refuse to recognise your best M.D.'s and Fellowships because a few years ago some of the licences were comparatively easy to obtain. We deny that European boards cannot tell the difference between our genuine and bogus diplomas. The Annual Report of the Illinois State Board of Health gives each year the names, time of charter, requirements for graduation, \&c., of every college, genuine or fraudulent, existing now, or that ever did exist, in the United States and Canada. By referring to it, it will be seen that the Buchanan and other bogus Colleges were closed by legal process, disproving the statement made by Mr. Martin that "similar deficiencies exist in other States," from which you were led to believe that seven or more persons could charter a College of any kind anywhere in the United States. I am, Sirs, yours faithfully,

De WitT C. NewMan, M.D.

Spokane Falls, Wash., May 1:th, 1890.

\section{THE STAMPING-OUT SYSTEM AS A SUBSTI-} TUTE FOR VACCINATION.

\section{To the Editors of THE LANCET}

SiRs,-In answer to Mr. Henry Taylor: Leicester has for many years relied upon notitication and isolation, and has enjoyed an immunity from small-pox. Sheffield, relying upon vaccination, neglected notification and isolation, and there was a very serious epidemic of small-pox. How can the immunity of Leicester be explained by "the presence of a large number of vaccinated people, who form a sanitary cordon round any infective centre," when at Sheffield this "sanitary curdon" was of no avail? The measures which I would venture to advocate for the suppression of small-pox are the principles of sanitation in the widest sense. To sum them up : (1) Prevention of filth and overcrowding; (2) compulsory notification; (3) compul sory isolation ; (4) disinfection ; (5) cremation. In the last century, owing to notification and isolation, small-pox was "never epidemical" in Rhode Island. At the present day our Anstralian colonies owe their immunity from epidemic small-pox to notification and isolation, and by these measures the disease when imported is promptly stamiped out. I am, Sirs, yours faithfully,

King's College, London, June 3rd, 1890 EDGar M. Crookshank.

\section{INFLUENZA IN BRAZIL.}

To the Editors of THE LANCET.

SIRs,-It is a far cry to Brazil, and perhaps some benighted ones among your readers may think it so far as to be rather behind the tines; but it is not so much as they may

1 Annual Report of the Illinois State Board of Health. 